\title{
PRESENT STATUS OF THE CONSTANTS AND VERI- FICATION OF THE LAWS OF THERMAL RADIATION OF A UNIFORMLY HEATED INCLOSURE
}

\author{
By W. W. Coblentz
}

\section{CONTENTS}

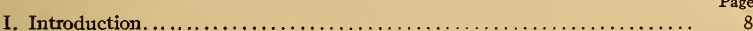

I. The Reichsanstalt investigations. ..................... 9

2. The Bureau of Standards investigations.................. 9

3. Object of the present paper.......................... II

II. Discussion of black-body radiation, radiators, and shutters........... II

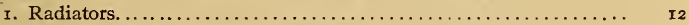

2. Water-cooled shutters and diaphragms..................... $1_{3}$

3. Statement of the laws of radiation........................ I4

III. Discussion of various determinations of the coefficient of total radiation... I5

I. Bolometric methods of electric compensation................ $\mathbf{r}_{5}$

(a) Observations of Kurlbaum...................... $\mathbf{1}_{5}$

(b) Observations of Valentiner....................... ${ }_{16}$

(c) Observations of Gerlach......................... 18

(d) Observations of Coblentz........................ 20

(e) Observations of Kahanowicz.................... 24

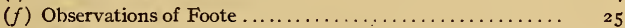

(g) Observations of Puccianti....................... ${ }_{25}$

2. Thermometric methods with "black" receivers............ 27

(a) Observations of Féry.......................... 27

(b) Observations oi Féry and Drecq.................. 27

(c) Observations of Bauer and Moulin................. 28

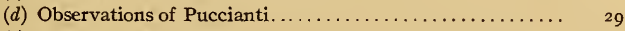

(e) Observations of Keene......................... 30

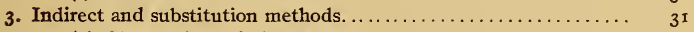

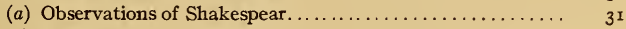

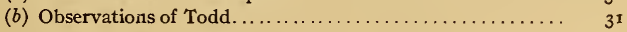

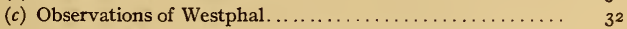

(d) Deductions of Lewis and Adams.................. 33

IV. Discussion of various determinations of the constant of spectral radiation. 34

(a) Observations of Paschen............................. 35

(b) Observations of Lummer and Pringsheim................ 37

(c) Observations of Warburg and Collaborators................... 38

(d) Observations of Coblentz........................... 39

V. Verification of the laws of thermal radiation of a uniformly heated inclosure........................................... 43

I. The formula and the coefficient of total radiation............. 44

2. The formula and the constant of spectral radiation.............. 44

3. Confirmatory evidence................................. 44

VI. Bibliography............................................. ${ }_{46}$ 


\section{INTRODUCTION}

This seems to be an appropriate time for a retrospect of past accomplishments and for a starting point once more in the determination of the constants of thermal radiation, which investigations everywhere have suffered much from interruption during the past six years.

The various determinations of the numerical values of the constants of radiation have been hampered by the lack of exact knowledge of numerous contributory constants which enter into their evaluation.

Among these factors are the temperature scale, the absorptive coefficients and refractive indices of the prisms used, the correction for atmospheric absorption, and the correction for reflection from the radiometer receivers.

When the writer began studying this subject, about I 4 years ago, it appeared desirable to determine more exactly the numerical values of the contributory constants, first of all, and then take up the determination of the constants of thermal radiation. At this day it is quite evident that such a procedure would have been the most efficient in obtaining the desired results. While such a program could not be fully carried out, some progress was made by determining the diffuse reflection of various substances, ${ }^{1}-$ for example, plantinum black-the absorption constants of quartz, ${ }^{2}$ and the correction for atmospheric absorption..$^{3,4}$ Somewhat similar experiments have been made by Warburg ${ }^{5}$ on the absorptivity of quartz and by Gerlach ${ }^{6}$ on atmospheric absorption.

Instead of a unified program of research, we find that, while one set of experimenters was engaged in establishing the temperature scale, another experimenter was determining the optical constants of the prism material; and a third group, using both the temperature scale and the optical constants, was attempting to determine the radiation constants. In turn, the first set of experimenters had to apply the results of those working on the radiation constants in order to verify and extrapolate the temperature scale beyond that attainable with the gas thermometer. In the meantime, the second experimenter improved his measurements of the optical constants (refractive indices) of the prism material (fluorite and quartz), while a fourth entered the field and added refinements by determining the temperature coefficients of these refractive indices. This in turn necessitated the recalculation of the prism calibration

${ }_{1}^{1}$ References are given in bibliography on pages $46-48$. 
and the numerical values of the spectral radiation constants. Added to these difficulties is the constant change in personnel, as is apparent from perusal of the title-pages of the published papers. The foregoing is an impersonal statement of the difficulties under which experimenters have been laboring. Fortunately, the spectral radiation observations are in terms of the scale of the spectrometer circle, and if the necessity arises, as described on a subsequent page, one can revise the corresponding wave lengths and recalculate the constants.

As a result of these various difficulties there is scarcely a determination of the constant $\sigma$ of total radiation, and of the constant $C$ of spectral radiation, which does not require corrections, some of which are obvious and could have been made by the experimenter.

It seems appropriate to point out specifically some of the difficulties experienced by the two national laboratories.

\section{THE REICHSANSTALT INVESTIGATIONS}

The determinations of the radiation constants, made at the German Reichsanstalt during the past two decades, involved measurements extending to about $1600^{\circ} \mathrm{C}$, or even higher, and hence they have suffered from both the lack of knowledge of the temperature scale and of the refractive indices of the prisms used. In the later work the determination of the temperature scale was rightfully combined with the measurements of the radiation constants, instead of having the former measurements made in a separate laboratory.

The published papers do not state whether an attempt was made to harmonize the various determinations of the refractive indices of fluorite. The most recent work was done with quartz prisms, and the determination of the refractive indices of quartz was undertaken, ${ }^{7}$ but as yet no data have been published.

\section{THE BUREAU OF STANDARDS INVESTIGATIONS}

The determinations of the radiation constants, especially the more recent ones, made at the Bureau of Standards, have suffered but little from a lack of knowledge of the temperature scale, owing to the fact that the radiators were not operated at a temperature much above $1200^{\circ} \mathrm{C}$, and usually near the melting point of copper-1083 ${ }^{\circ} \mathrm{C}$. The chief difficulty has been the lack of exact knowledge of the refractive indices of fluorite; or, as it appears from the present inquiry into the matter, the lack of 
exact knowledge of the refractive index of the yellow sodium line, and especially the yellow helium line which was used as a reference point in calculating the infra-red calibration of the prism.

The size of the apparatus used in determining indices of refraction is an important element in the accuracy attained. Langley ${ }^{8}$ used a spectrometer having an image-forming mirror of over 4.5 meters focal length, in an inclosure which could be kept at a constant temperature. Paschen's ${ }^{9,10,11,12}$ apparatus had an imageforming mirror of only $\mathrm{I} / \mathrm{IO}$ to $\mathrm{I} / \mathrm{I} 2$ that of Langley's, and hence could not compete with it in accuracy. Hence, from the beginning, more weight should have been given to Langley's measurements. On applying Micheli's ${ }^{13}$ temperature coefficients of refraction, Paschen's various determinations are found in good agreement with those published by Langley ${ }^{8}$ whose reference point is the solar absorption line (the "A line") $\lambda=0.7604 \mu$; refractive index $n=1.431020$ for fluorite at $20^{\circ} \mathrm{C}$. From this point into the infra-red, the various determinations of the infrared refractive indices of fluorite are in excellent agreement.

However, the fiducial line in this Bureau's spectroradiometry is the yellow helium line. From the present study of the data it appears that prior to 1913 the refractive indices of fluorite, for the visible spectrum, and in particular that of the yellow helium line $\lambda=0.5^{8} 75^{8} \mu$, were not known with sufficient accuracy to meet the present-day demands for refinements in the radiation constants. As a result, erroneous wave lengths were assigned to the infra-red (minimum deviation) settings of the spectrometer circle. This error is only $3^{\prime \prime}$ (true value, $6^{\prime \prime}$ ) in the Wadsworth system of spectrometer settings, and hence scarcely observable experimentally. However, it enters as a constant error of 0.3 to 0.4 per cent in the calculations of the calibration curve. Errors of such small magnitude were considered insignificant eight years ago, when there was a disagreement of $\mathrm{I}$ to 2 per cent, or even more, in the various determinations of the constant of spectral radiation.

As will be shown on a subsequent page, using Paschen's ${ }^{12}$ recent measurements of the refractive index of fluorite for the yellow helium line (which measurements were made with a new and very accurately graduated spectrometer), all the apparent errors seem to be eliminated from this Bureau's determination of the constant of spectral radiation, which is now in good agreement 
with the value that is to be expected from the Bureau's determination of the constant of total radiation ${ }^{15}$ and from theoretical considerations. ${ }^{4}$

\section{OBJECT OF THE PRESENT PAPER}

In previous papers ${ }^{15,4}$ corrections were applied to the determinations of the radiation constants made by various experimenters. The object of the present paper is to make an up-to-date examination into the various instruments and methods employed in these various determinations and to give an estimate of the accuracy of the results therewith obtained.

At first glance, the various determinations of these constants appear to cover a wide range of numerical values. This is especially true of the values of the coefficient of total radiation, in which all sorts of ill-considered methods have been used. Moreover, no corrections were made for atmospheric absorption of the thermal radiation in its passage from the radiator to the receiver. As will be shown presently, most of these older determinations are in remarkably close agreement with the newer ones after making obvious corrections for atmospheric absorption and for reflection of the incident radiation from the receiver.

This paper does not include a discussion of the attempts which have been made to determine the constant, $C$, by means of an optical pyrometer, which at least in its ordinary form can not be considered an instrument of high precision. There are many difficulties to be overcome before one can conclude that the data so obtained are trustworthy. One of the uncertainties is the effective wave length of the red glass used in the eyepiece of the pyrometer. Other difficulties are encountered when using a spectral pyrometer. Also the temperature scale is in doubt. Hence recent experimenters have not attempted to determine $C$, but have reversed the process and, working on the assumption that $C$ is a certain value, say, $C=14350$, have determined the melting point of palladium. This seems to be the preferable procedure.

\section{DISCUSSION OF BLACK-BODY RADIATION, RADIATORS, AND SHUTTERS}

In order to arrive at an intelligent understanding of what has been accomplished in the determination of the constants of radiation, and in order to indicate the way to future progress in this subject, it is important to consider very briefly some of the 
conceptions, as well as some of the most recent instruments and methods used in the production and measurement of the radiation from a uniformly heated inclosure, or so-called black body.

Every substance has a characteristic emission spectrum. On the other hand, the emission spectrum of a uniformly heated cavity is independent of the composition of the material forming the walls of the inclosure. It is a function only of the temperature.

The emission of thermal radiation from and the absorption of thermal radiant energy of all wave lengths entering into the cavity is complete. In a material substance this can occur only on the short-wave length side of the region of anomalous dispersion where the absorptivity is high, but where the reflecting power is practically nil; for example, in quartz ${ }^{29}$ selenite and aluminum oxide, in the region of $7 \mu$ to $\mathrm{Io} \mu(\mu=0.00 \mathrm{Imm})$.

Modern conceptions of black-body radiation are the result of slow development from such simple experiments as those of Draper ${ }^{19}$ who found that the interior of a rifle barrel became luminous at a certain temperature; of Christiansen ${ }^{21}$ who observed that the scratches and conical-shaped holes in an incandescent metal surface were brighter than the smooth surface and of St. John ${ }^{22}$ who found that the selective emission, commonly observed in the rare oxides, disappeared when these substances were heated in a uniformly heated porcelain tube.

\section{RADIATORS}

The modern uniformly heated cavity or so-called black body is the result of such observations and facts as just enumerated. It is the invention of Wien and Lummer ${ }^{23}$ and, for attaining fairly high temperatures, such as are used in many of the investigations mentioned in a subsequent part of this paper, consists of a diaphragmed porcelain tube wound with platinum ribbon, which is electrically heated.

In the modification used by the writer ${ }^{30}$ the radiator consisted of two concentric tubes suitably wound with platinum ribbon in order to obtain a uniform temperature throughout a great length of the interior of the radiator, as shown by Waidner and Burgess. ${ }^{31}$ The use of platinum ribbon instead of thick platinum wire eliminates local nonuniformity of temperature in the porcelain tube.

In radiators of this type the porcelain tubes sag on heating to $1200^{\circ} \mathrm{C}$. To overcome this difficulty, in the determination of the radiation constants, to be described presently, the writer ${ }^{30}$ placed a wedge-shaped fragment of porcelain, with a sharp edge, 
about $2 \mathrm{~mm}$ long, about 25 to $30 \mathrm{~mm}$ to the rear of the radiating diaphragm. This support causes no local cooling, and it preserves the life of the radiator. Further improvements were made in the completeness of the emission of the radiation by painting the inside walls and the front side of the radiating diaphragm with a mixture of chromium oxide and cobalt oxide. Since these oxides become electrically conducting at $\mathrm{I} 200^{\circ}$, the front thermocouple was completely inclosed in a porcelain insulating tube. The short piece of porcelain which lies across the radiating wall of the black body was covered with cobalt oxide. Since the cobalt oxide did not adhere well to the porcelain tube, the latter was first covered with a thin layer of iron oxide, obtained by wetting the porcelain tube with writing ink which was burned into the tube. The cobalt oxide paint was then appiied and also burned upon the tube by means of a blast lamp. After replacing the thermocouple, inclosed in this short tube, in the radiator, the whole interior was again painted with a mixture of cobalt and chromium oxides.

The cobalt oxide has a high temperature coefficient of absorption so that it appears black on slight heating. Its emission spectrum ${ }^{29}$ is continuous, so that there is less difficulty in producing a perfect radiator than when the radiating inclosure is of white porcelain. However, porcelains which have a low melting point are less selective in their emission than the "Marquardt porcelain," from which are made the black bodies ordinarily used.

\section{WATER-COOLED SHUTTERS AND DIAPHRAGMS}

In discussing the relative merits of the various determinations of the radiation constants, and in particular the coefficient of total radiation, the writer will have occasion to refer frequently to the use, or misuse, of shields for preventing the receiver from being heated by the radiator, and of shutters for exposing the receiver to radiation. It is, therefore, important to consider briefly the functions of this apparatus.

The determination of the coefficient of total radiation usually consists in noting the heat interchange when the receiver is exposed to two radiators which are at widely different temperatures, say 0 and $100^{\circ} \mathrm{C}$; that is, ice and boiling water. The radiator at the lower temperature may be, and usually is, used as a shutter. If the temperature of the shutter is lower than that of the receiver, the latter radiates to the shutter. Hence, it is important to have the receiver face a large (say, water-cooled) diaphragm, maintained at a constant temperature, back of which is placed the $15787^{\circ}-21-2$ 
shutter and the radiator. In this manner the surrounding conditions, facing the receiver, are not changed when the shutter is moved in order to expose the receiver to radiation.

There is no doubt that some of the unusual results obtained in the determination of the radiation constants are attributable to the operation of the shutter under such conditions that the receiver did not face uniform conditions when the shutter was opened in making the measurements.

Experience shows that the arrangement of the shutter should be similar to that used ${ }^{3}$ (loc. cit., p. $5^{16}$, Fig. 5) in the determination of the coefficient of total radiation. In this arrangement the water-cooled shield employed consisted of a tank $35 \mathrm{~cm}$ in diameter and $1.5 \mathrm{~cm}$ in thickness, which faced the radiator, and a second tank, $20 \mathrm{~cm}$ in diameter and $3 \mathrm{~cm}$ in thickness, which faced the radiometer. The water-cooled shutter, consisting of a thin metal box 3.5 by 3.5 by $0.8 \mathrm{~cm}$, was operated in vertical ways between these two shields. A mercurial thermometer was used to measure the temperature of the water flowing through this shutter. The side of the shutter facing the radiometer was smoked in a sperm candle, and, in connection with the conical-shaped opening (painted black and smoked) in the water-cooled diaphragm which faced the radiator, it formed a miniature black body the temperature of which remained constant throughout a series of measurements.

\section{STATEMENT OF THE LAWS OF RADIATION}

The law of total radiation, generally called the Stefan-Boltzmann law, ${ }^{17}$ states that the total emission of thermal radiation, $R$, of all wave lengths passing from a uniformly heated inclosure, at temperature $T_{1}$ to another body at a temperature $T_{0}$ is proportional to the difference of their absolute temperatures, to the fourth power, or

$$
R=\sigma\left(T_{1}{ }^{4}-T_{0}{ }^{4}\right)
$$

In this formula $\sigma$ is the coefficient or constant of total radiation under discussion. The numerical value of this coefficient is of the order $\sigma=5.7 \times \mathrm{IO}^{-5} \mathrm{erg}$ per $\mathrm{cm}^{2}$ per sec. per deg. ${ }^{4}$ In this paper only the first three significant figures will be mentioned; for instance, $\sigma=5.32$.

The law of spectral radiation, which specifies the distribution of thermal emission intensities in the spectrum of the radiation 
emitted by a uniformly heated inclosure, or so-called black body, is best represented by Planck's ${ }^{18}$ formula

$$
E_{\lambda}=C_{1} \lambda^{-5}\left(e^{c} /^{\lambda T}-\mathrm{I}\right)^{-1} .
$$

In this formula the constant $C$ determines to a great extent the shape of the isothermal spectral-energy curve. Suffice it to say that these laws are based on well-grounded theoretical foundations, and after almost two decades of discussion they remain unchanged.

\section{DISCUSSION OF VARIOUS DETERMINATIONS OF THE COEFFICIENT OF TOTAL RADIATION}

It has been shown by Stefan, ${ }^{16}$ Schneebeli, ${ }^{25}$ Wilson, ${ }^{26}$ Lummer and Pringsheim, ${ }^{24}$ Valentiner, ${ }^{27}$ and others ${ }^{3,15}$ that the total radiation emitted from a uniformly heated cavity is proportional to the fourth power of the absolute temperature. The measurements extend over a temperature range of perhaps $1500^{\circ} \mathrm{C}$. They verify the fourth power law within the accuracy of the temperature scale and the general errors of observation, which are small owing to the fact that the measurements are relative.

The evaluation of the coefficient of thermal radiation in absolute measure is an extremely difficult task which has been attempted by numerous experimenters, whose data will now be considered.

The early determinations of the coefficient of emission of a substance (for example, blackened plates or balls of glass or copper) by Lehnebach,,$^{34}$ Christiansen, ${ }^{35}$ and others are of great historical interest, but they can not be considered in connection with presentday determinations of the coefficient or constant, $\sigma$, of total radiation of a uniformly heated inclosure.

\section{BOLOMETRIC METHODS OF ELECTRIC COMPENSATION}

(a) Observations of Kurlbaum. ${ }^{36}$-The first determination of the constant of total radiation in absolute value, by a method which is free from the gross experimental errors that are inherent in the work, was made by Kurlbaum.

The principle of the method is as follows: Three branches of a Wheatstone bridge (bolometer) consist of thick manganin wires which are not affected by a change in current through the bridge. The fourth branch consists of thin bolometer platinum, the resistance of which is affected by a change in current in the bridge. Starting with the bridge balanced, the bolometer branch of thin 
platinum, at a distance of $\mathrm{I} 8$ to $20 \mathrm{~cm}$, is exposed to the radiation from a black body at $100^{\circ} \mathrm{C}$, and the change in resistance (or galvanometer deflection) is noted. With the bolometer branch shielded from radiation, the bridge current is varied until the change in resistance in the bolometer branch is equal to that attained when exposed to radiation. In other words, the bridge current is increased by a sufficient amount to produce the same galvanometer deflection as was caused by radiation falling on the bolometer strip. From a knowledge of the change in the bridge current, the bolometer resistance, etc., Kurlbaum was able to compute the energy input. He used two very different surface bolometers and found very concordant values. He found a value of $\sigma=5.32$. In a subsequent communication ${ }^{37}$ he made a correction of 2.5 per cent for loss by reflection from the platinum black surfaces of the bolometer. This gives a value of $\sigma=5.45$. The writer ${ }^{1}$ has determined the reflecting power of platinum black and has found that, using the blackest obtainable deposits, the reflecting power is almost 2 per cent for wave lengths at 8 to $9 \mu$. An examination of six surface bolometers ( 12 branches or 24 surfaces of about 3 by $4 \mathrm{~cm}$ area), purchased abroad, showed that all of them had microscopically small bright patches of bare platinum, and that none of them were as black as the samples upon which the reflectivity measurements were made. ${ }^{1}$ These bright areas would increase the loss by reflection. From this it appears that Kurlbaum's correction to his work is none too large.

(b) Observations of Valentiner. ${ }^{27}$-This method of measuring the coefficient of total radiation by means of a large surface bolometer was continued by Valentiner, who found quite different values, depending upon the blackness (kind) of radiators employed, which were heated as high as $145^{\circ} \mathrm{C}$. For the two blackest radiators (the steam-heated radiatior "W.S. K." and the electrically heated unblackened porcelain tube radiator "G. S. K.") he found a value of $\sigma=5.36$.

In a subsequent paper, ${ }^{38}$ he made a correction of about 4 per cent for various causes (for example, I per cent for lack of blackness of the radiator, 2.5 per cent for reflection from the bolometer, etc.) giving a value of $\sigma=5 \cdot 58$. No correction was made for atmospheric absorption.

The numerical values of the various determinations made by Valentiner, upon any one radiator, have a range of about 3 per cent, which was usually higher than allowable in order to ascertain the effect of atmospheric absorption in a space of 30 to $50 \mathrm{~cm}$. How- 
ever, when using a larger porcelain tube radiator, ${ }^{27}$ "G. S. K.," the distances were rather longer than usual, being, respectively, 89 to I $25 \mathrm{~cm}$, and the effect of absorption seems unmistakable. The value of the radiation constant is about 2 per cent smaller for the greater distance, i. e., an increase of $35 \mathrm{~cm}$ in optical path introduced an absorption of about 2 per cent. It is difficult to say how great a correction should be applied to Valentiner's values in order to eliminate atmospheric absorption. The observations were made in the winter, when the humidity was, no doubt, much lower than for the test made by the writer, ${ }^{15}$ in which an absorption of over 5 per cent was found in an air path of $124 \mathrm{~cm}$, the temperatures of the radiator being of the same order as used by Valentiner. A conservative estimate of the correction to Valentiner's data, for absorption by atmospheric water vapor and carbon dioxide is 2 to 3 per cent. This increases Valentiner's value to $\sigma=5.68$ with a possibility of the value being as high as $\sigma=5.75$, which is in remarkably close agreement with the various determinations made by other methods. That a correction of not less than I per cent is to be applied to these data is indicated in Gerlach's ${ }^{44}$ recent work on atmospheric absorption of black body radiation.

The surface bolometers used by Kurlbaum and by Valentiner consisted of two grids of thin platinum foil, placed one back of the other, with the surfaces overlapping. In this manner a continuous surface is formed, but part of the rear bolometer strips are shielded from the radiation incident on the front strips. The operation of the receiver is, therefore, unsymmetrical. Gerlach ${ }^{40}$ has discussed the effect of this overlapping and has shown that in some cases it might lower the value of the observed radiation constant by a very considerable amount. The writer ${ }^{39}$ has found that, using one bolometer strip back of the other, 50 per cent of the energy, incident upon the first receiver, is reradiated to the rear one. In the reverse process of heating the strip electrically, this effect would enter symmetrically and a low value of $\sigma$ would result.

It was found by Kurlbaum and by Valentiner that the rate of temperature rise was different for heating the bolometer by absorption of radiation and by electrical heating. The low values of the radiation constant obtained by Valentiner are explained,,$^{40}$ in part, as the result of reading the galvanometer deflection before temperature equilibrium was fully attained. Callendar ${ }^{41}$ has described surface bolometers which would overcome some of the defects of conduction, etc. However, using radiators at 600 to 
$1000^{\circ} \mathrm{C}$, there is no need of using s11ch large receivers with the unavoidable defects just noted.

(c) Observations of Gerlach. ${ }^{42},{ }^{48}, 108$-The following method is not exactly bolometric in principle, but it may be considered here, since its virtues have been under discussion in connection with the results obtained by the bolometric methods just mentioned. Gerlach determined the constant of total radiation, $\sigma$, by a modification of Ångström's electric compensation pyrheliometer. In the original pyrheliometer of Ångström, ${ }^{43}$ there are two thin, narrow sheets of manganin to each of which is attached one junction of a thermoelement which is joined through a galvanometer. One of these manganin strips is exposed to solar radiation. Through the other manganin strip is passed an electric current of such strength that it is heated to the same temperature as is the strip which is exposed to solar radiation. The equality of temperature is indicated when there is no current flowing through the galvanometer.

In the instrument as used by Gerlach there is but one strip of manganin which is $0.0 \mathrm{~mm}$ in thickness, and 2 to $4 \mathrm{~mm}$ wide (length 2.7 to $3 \mathrm{~cm}$ ). At the back of this manganin strip and close to it was a thermopile of 45 elements (joined through a galvanometer) which is heated by radiation from the manganin strip, thus differing from Ångström's device in which a single thermojunction was heated by conduction from the manganin strip. The idea of using many junctions was to integrate over the whole strip, thus eliminating any irregular heating caused by inequalities in the thickness of the manganin strip, which was blackened electrolytically with platinum black. This manganin strip was heated electrically to the same temperature as that attained by the strip when exposed to the radiation from a black body. From a knowledge of the resistance of the strip and the electric current it was possible to determine the energy input, and hence the value of the radiation constant.

Gerlach experienced some difficulty in determining when he had exact compensation when heating the receiver electrically and radiometrically. Covering the sides of the receiver with knife-edged slits had no effect upon the radiation constant; but shielding the ends of the manganin strip from radiation caused the value of $\sigma$ to increase from $\sigma=5.83$ for the unshielded ends to a constant value of $\sigma=6.14$ when the shields covered $1.5 \mathrm{~mm}$, or more, of the ends of the strips. This is owing, perhaps, to heat conduction from the 
ends and to the fact that in heating the strip electrically no correction was made for the excess electrical energy used in the ends of the receiver, which were not exposed to radiation. In practice he exposed the whole length of the receiver to radiation, claiming that the heat conducted from the ends is the same when the metal strip is heated radiometrically and electrically. ${ }^{44}$

The weak point in the device appears to be the uncertainty of (I) the effective length of the receiver, which is exposed to radiation, and (2) the length which is contained between the potential terminals and which is used in the evaluation of the energy in absolute measure. In the instrument used by the writer, ${ }^{3}, 15$ this uncertainty was eliminated by placing the potential terminals upon the receiver, and at some distance from the heavy electrodes; thus providing uniform heating over a greater length of the receiver than is actually used in evaluating the constant. This seems to be the logical way to use such a receiver.

The mean value obtained by Gerlach is $\sigma=5.803$. He made no correction for losses by reflection ( 2 per cent). This was done by Paschen, ${ }^{45}$ who gives the value $\sigma=5.9$.

Gerlach's value is based upon the determinations made with four receivers, the individual values of which depend somewhat upon the receiver, as was observed by the writer. ${ }^{3}$ No attempt was made to remove the atmospheric water vapor from the space between the radiator and the receiver. There is a systematic decrease of $\mathrm{I}$ to 2 per cent in the radiation constant for an increase of 32 to $42 \mathrm{~cm}$ in the distance of the receiver from the radiator.

The work of Gerlach aroused considerable discussion among experimenters previously engaged on this same problem. This brought forth a very considerable amount of laborious experimental work by Gerlach ${ }^{46}$ in defense of his method, in which he showed that his apparatus gave the same values as when operated by the bolometric method employed by Kurlbaum. ${ }^{36}$

In subsequent investigations, Gerlach determined the effect of atmospheric absorption ${ }^{6}$ and of blackening the receiver ${ }^{47}$ upon the radiation constant. He operated the radiator at higher temperatures (to $450^{\circ} \mathrm{C}$ ), but the radiometric apparatus remained the same as in the earlier work. With this outfit his ${ }^{48}$ new value of the coefficient of radiation, uncorrected for reflection of radiation from the receiver and for atmospheric absorption, is decidedly lower than that previously observed under similar conditions, being of the order $\sigma=5.6$ to 5.7 , as observed by the writer. Applying a correction of about 1.7 per cent for reflection ${ }^{1}$ and, depending 
upon the temperature of the radiator, a correction of 0.2 to $\mathrm{I} .2$ per cent for absorption of $\mathrm{CO}_{2}$, the mean value of $5^{2}$ independent sets of measurements is $\sigma=5.85$. In a recent discussion of the constant of total radiation, Gerlach ${ }^{106}$ places his value at $\sigma=5.80$ when corrected for reflection.

Gerlach has done an enormous amount of experimental work and his determination is one of several which should be a convincing demonstration that the extreme values of $\sigma=5.3$ to 6.5 are subject to correction, in so far as the corrections can be determined.

(d) Observations of Coblentz.,15,4-This research was undertaken after making a study of the instruments and methods used in the earlier determinations, and an effort was made to embody the good features and eliminate the defective ones. It is, therefore, proper to discuss the work in considerable detail.

In designing the apparatus, an attempt was made to embody black-body conditions in the radiator (including the shutter and the receiver, as described under Section II). The lack of blackness of the radiator has been discussed by Wien and Lummer, ${ }^{23}$ who gave a method for computing the correction for the opening in the radiator, on the assumption that the inclosure is spherical and diffusely reflecting. The amount of energy that can escape by diffuse reflection through the opening is determined practically by the size of the opening as compared with the total area of the interior of the radiator. In the porcelain tube radiator used in the present work the interior is uniformly heated over a length of 8 to $10 \mathrm{~cm}$. However, for the purpose of the present computation, a length of only $2.5 \mathrm{~cm}$ which is defined by the first diaphragm, is considered. The area of the inclosure is $37.6 \mathrm{~cm}^{2}$ and that of the opening is $3.1 \mathrm{~cm}^{2}$ Or the basis that the reflecting power of the interior of the painted radiator is 7 per cent (loc. cit., ${ }^{3}$ p. 523 , Table 3 ), the loss of energy by diffuse reflection through the inner diaphragm is 0.63 per cent. Using an unpainted Marquardt. porcelain radiator, the coefficient of radiation is decreased by about I per cent (loc. cit., ${ }^{15}$ p. $57 \mathrm{I}$ ), showing that the question of lack of blackness of the radiator is important.

For a receiver ${ }^{50}$ it was decided to use a modified Ångström pyrheliometer ${ }^{43}$ embodying novel features which had not yet been tried by others. In order to reduce the heat capacity of the manganin receiver and provide better insulation, the thermopile of bismuth and silver, having a continuous receiving surface, was placed a short distance back of the receiver. The apparatus used by Gerlach embodied this same idea. 
The crucial and novel part of the apparatus was a receiver with potential terminals attached thereto, at a sufficient distance from the ends to avoid the uncertainty of the effective length of the receiver which is exposed to radiation and the length utilized in making the potential measurements. These potential wires, which were from 0.003 to $0.025 \mathrm{~mm}$ in diameter, defined the effective length of the central part of the receiver (which was utilized in the radiation measurements) more accurately than seems to be possible by measuring the distance between two heavy electrodes to which the receiver is soldered and to which the potential terminals are attached. By exposing the whole length of the receiver to radiation, conduction losses from the ends of the receiver do not enter the problem.

By means of an extra terminal the effect of the presence of the potential terminals was determined ${ }^{3}$ and found negligible, viz, 0.3 per cent. The method of finding the difference of potential between two potential terminals seems more certain than to find the difference of potential between two heavy electrodes as used by Gerlach. ${ }^{42}$ For, when the soldering is well done, a narrow band of solder protrudes from under the heavy electrode and fills up the sharp edge where the receiver joins the electrode. Hence the effective length of the receiver is less than that measured from the sharp edge of the electrode, and an erroneous value is assigned to the area of the receiver.

The operation of this type of radiometer would have involved the use of a hemispherical mirror placed in front of the receiver..$^{3,1,49}$ This may introduce errors when the strip is heated by electrical means. Hence, after conferring with specialists in geometrical optics who were in agreement with the writer's opinion that a reflecting inclosure is likely to introduce errors, the receiver was used without the hemispherical mirror, which was employed in a separate experiment to determine the diffuse reflection ${ }^{1}$ from lampblack and platinum black, and finally, in determining the loss by reflection from some of the receivers actually used in making these observations. Hence, the loss of radiation incident upon the receivers was probably accounted for as accurately as it would have been by employing a "blackening" device in front of the mirror.

In order to test the question of the accuracy of the corrections used for eliminating the loss by reflection, a series of observations was made on receiver No. Io. In this test the slits in front of the receiver and all other conditions remained unchanged (not so in 
No. 6). The only variation was in smoking the platinum-black receiver with a sperm candle after making the first set of observations. The reflecting power of platinum black was taken to be 1.7 per cent ${ }^{4}$ and that of lampblack 1.2 per cent. The respective determinations are $\sigma=5.822$ and $\sigma=5.814$. They differ only by about 0.1 per cent, which is very satisfactory and shows that the reflection factors were (relatively, at least) well determined.

Subsequent tests showed that in this outfit the effect of atmospheric absorption was less than o.I per cent. ${ }^{4}$ This conclusion is substantiated by recent measurements made by Gerlach. ${ }^{6}$

The thermopile was connected with a magnetically (unusually well) shielded ironclad Thomson galvanometer of special design ${ }^{40,51}$ which served merely to indicate the relative rise in temperature of the receiver when exposed to radiation and when heated electrically.

The method of observation consisted in exposing the receiver to radiation and noting the galvanometer deflection; then in heating the strip by passing an electric current through it to give, within I per cent, the same deflection. The measurements of the power put into the strip were made with the same potentiometer used in measuring the temperature of the radiator. No difficulty was experienced in determining temperature equilibrium on heating the receiver by radiation and by electrical means.

The exact amount of energy necessary to cause the same deflection as that produced by absorbing radiant energy is obtained by multiplying the observed energy input by the ratio of the galvanometer deflections. This gives the "constant" of each receiver. In order to reduce all the measurements to a common basis, and at the same time obtain a value of the coefficient, or the so-called Stefan-Boltzmann constant, of total radiation, the custom of previous experimenters was followed in reducing the data.

The radiator was operated at a temperature of 800 to $1000^{\circ} \mathrm{C}$, within which range the temperature scale is quite well determined.

The data obtained with receivers Nos. 8 and 9 are not included in the final value, because, at the time the measurements were made, they were known to be defective (as was quite fully explained in the original paper), and hence the reliability of the results would be open to question. For example, receivers Nos. 8 and 9 , which were of platinum, were heated to redness to clean and brighten their surfaces before covering them with platinum black. As a result, the solder at the ends alloyed with the platinum, in one case leaving a large hole between the potential ter- 
minal and the electrode. These receivers should never have been used for precision measurements.

To the data (304 pairs of measurements) obtained with ro receivers a correction of 1.2. per cent for losses by reflection was applied to measurements made with receivers covered with lampblack (soot), and a correction of 1.7 per cent to measurements made with receivers covered with platinum black. The reflection from a receiver covered with platinum black, then smoked, is I.2 per cent. As just mentioned these corrections were determined by direct measurements upon some of the receivers used in this investigation and by comparison of the surfaces of the other receivers with samples of lampblack whose reflection losses had been determined in a previous investigation. ${ }^{1}$ The value of the coefficient of total radiation, after applying the corrections just mentioned, is

$$
\sigma=\left(5.722 \text { 土0.012) } \times 1_{\mathrm{IO}^{-12}} \text { watt } \mathrm{cm}^{-2} \mathrm{deg} .^{-4}\right.
$$

If we took the average of the measurements made with all of the receivers, including the two defective ones, the value of the radiation constant would be increased by only about 0.3 per cent, or $\sigma=5.74$. This is owing to the fact that these two defective receivers represent only 44 out of a total of $34^{8}$ pairs of measurements.

No correction was made for absorption by atmospheric carbon dioxide, because in actual test, ${ }^{4}$ the effect of the presence of $\mathrm{CO}_{2}$, to the extent of o.I per cent, could not be detected. However, assuming that the effect is as large as indicated by Gerlach's ${ }^{6}$ measurements, this correction might perhaps amount to 0.1 per cent to 0.2 per cent, thus increasing the value to $\sigma=5.73$.

The method of operation is unsymmetrical in that when the receiver is exposed to radiation the heating is produced in the lampblack surface, while in passing an electrical current through the strip the heat is generated within the receiver. However, from the data obtained with receivers differing ten times in thickness, and covered with different kinds and thicknesses of absorbing material, it appears that the manner of heating the receiver has but little effect upon the final results.

For any one receiver, operated under different conditions, the precision attained is usually much better than I per cent. For the different receivers the maximum range in the value of $\sigma$ is of the order of 1.5 to 2 per cent. This seems to be independent of 
the length and width of the receiver and of the kind of slits used. The accuracy attained with this method of evaluating energy in absolute measure, as estimated by the departure of individual determinations from the mean value, appears to be of the order of I per cent.

Recently, Gerlach ${ }^{10 e}$ has discussed these data, and, since his paper contains some inaccurate interpretations of this work, it is relevant to add a few comments in reply. A careful and unbiased examination of the original papers ${ }^{3}, 15$ will show (I) that receiver No. I, as well as Nos. 8 and 9, gave values which were greater than $\sigma=5.8 ;(2)$ that Nos. 8 and 9 were excluded from the beginning, ${ }^{15}$ because they were defective-not subsequently, ${ }^{107}$ because they gave values greater than $\sigma=5.8$, as Gerlach's remarks (loc. cit., ${ }^{106}$ p. 81 ) would leave one to infer; and (3) that the "Good series" mentioned by Gerlach refers to experimental conditions for series CX (just as in series CVI we read "Galv. unsteady") and has nothing to do with defects in the receiver itself which cause a constant error in the work. An examination of Gerlach's ${ }^{42}$ original paper (see Table 8 , loc. cit. ${ }^{42}$ ) shows that he also omitted from his final values data obtained with the defective receivers, which happened also to give abnormally high values. In fact, his first value is based upon only about one-half (4) of the total number of receivers constructed, while the writer's value is based upon ro out of 13 receivers.

(e) Observations of Kahanowicz. ${ }^{54}$ - The apparatus used by Kahanowicz, is essentially a modificatior: of the Angström pyrheliometer. ${ }^{43}$ The receiver was placed at the center of a spherical mirror with an opening in one side to admit radiation. In this manner the correction for reflection was eliminated. The shutter was close to the receiver. If its temperature was different from that of the water-cooled diaphragm which was before the radiator, errors in the radiation measurements would occur. As mentioned eleswhere in this paper, the shutter should be placed between the water-cooled diaphragm and the radiator to avoid a change in surroundings facing the receiver when the shutter is raised for making the radiation measurements.

The temperature range was from 260 to $530^{\circ} \mathrm{C}$. The distance from the radiator to the receiver was 35 to $55 \mathrm{~cm}$. A series of 28 measurements gave an average value of $\sigma=5.61$. Of this number I I gave a value of $\sigma=5.7$. Out of a series of four measurements made in December, 1916 , with the distance $d=56 \mathrm{~cm}$, three gave a value of $\sigma=5 \cdot 7$. 
No corrections were made for atmospheric absorption, which for the temperatures used is not negligible. In a previous paper (loc. cit., ${ }^{3}$ p. 576 ) it was shown that on removing the moisture (vapor pressure of Io to $12 \mathrm{~mm}$ ) from a column of air $5^{2} \mathrm{~cm}$ in length, the radiation constant was increased from $\sigma=5.4 \mathrm{I}$ to 5.55 , or about 2.6 per cent. Other measurements mentioned in the paper just cited indicate an absorption of 2 to 3 per cent of the radiations emitted by a black body at $1000^{\circ} \mathrm{C}$ for the average humidity of Washington. The vapor pressures at Naples are considerably higher than at Washington. From these, ${ }^{4}$ as well as Gerlach's, ${ }^{44,106}$ data it would appear that the corrections for atmospheric absorption must be at least I per cent. For the low temperatures at which the radiator was operated, a conservative estmate of the correction to the radiation data obtained by Kahanowicz is 1.5 to 2 per cent, or a value of $\sigma=5.69$ to 5.73 . In other words the Naples value of the coefficient of total radiation is comparable with other recent determinations which indicate a value of $\sigma=5 \cdot 7$.

(f) Observations of Foote. ${ }^{108}$ - It is of interest to record Foote's deductions of the probable value of the coefficient of total radiation as obtained in the course of an investigation of the Marvin pyrheliometer.

The receiver of this pyrheliometer consists of a silver disk about $45 \mathrm{~mm}$ in diameter and $3 \mathrm{~mm}$ in thickness, inside of which is a spirally wound insulated nickel wire in the form of a 3 -lead resistance thermometer This coil serves both as a thermometer and as a heater for calibrating the device by means of electrical energy.

Foote calibrated the instrument by the usual electric method and then radiometrically by exposure to the radiation of a black body. On the assumption that the coefficient of total radiation is $\sigma=5.7$, he found the two methods of calibration in agreement within the limit of the errors of observation.

(g) Observations of Puccianti. ${ }^{3}$ - The method of operation is just the opposite of that usually employed, and, in view of the small radiant energy exchanges involved, in comparison with the transfer of energy by heat conduction and by convection, this may perhaps be the weak point in his method.

Puccianti constructed a bolometer in the form of a black body, which is kept at room temperature. This black body really is the radiator. The other black body (which is really the receiver, 
consisting of a blackened glass bulb) instead of being at a higher temperature, as usually is the case, is at the temperature of carbon dioxide snow or of liquid air. He measured the electric power which had to be supplied to the first black body to keep the temperature constant in order to compensate for the energy lost by radiation to the second black body. He very ingeniously constructed two black-body bolometer branches exactly alike, the one to be exposed to the cold receiver and the other to be protected from it. Each of these bolometer branches consisted of a vessel of o.I $\mathrm{mm}$ sheet copper having the form of a cone and a frustum of a cone united at the bases. The internal surface was smoked. The external surface was polished, and upon it were wound two thin instlated wires. One of these wires, of iron, formed the bolometric branch, and the other wire, of manganin, was used as a heating resistance. The other two branches of the bolometer bridge were formed of resistance coils and the whole was connected with a galvanometer and storage battery as in any ordinary bolometer. The two sensitive black-body branches of the bolometer were in an evacuated vessel, which was kept in a tank of water.

Puccianti measured the (electrical) energy necessary for compensation to prevent the bridge from being unbalanced when one branch was exposed to the receiver. He obtained a value of $\sigma=5.96$.

The method is an ingenious variation from the usual procedure. The apparatus should have been constructed so that both bolometer branches could have been used as radiators. From the illustrations it appears that radiation from one branch could fall upon the other, which would introduce errors. Another uncertainty is the temperature and the manner of operation of the shutter. Tests might have been made to determine whether the bolometer remained balanced when a heating current was applied to both branches, without allowing one branch to radiate to the receiver. Furthermore, to repeat the herein oft-mentioned device, a heating coil should have been inserted temporarily within the radiator to determine the energy input as compared with the energy input required in the outer heating coils in order to maintain a balance. The device, as used, is unsymmetrical in that the heating coil is not in the proper place to operate the most efficiently. From this it appears that the constant is less than that indicated by these measurements. 


\section{THERMOMETRIC METHODS WITH "BLACK" RECEIVERS}

(a) Observations of Féry. ${ }^{55}$ - In order to eliminate the question of reflection from the surface, Féry, ${ }^{55}$ made a series of determinations of the radiation constant, $\sigma$, by means of a thermojunction which is formed into a long conical-shaped metal receiver, which is blackened on the inside. On the outside of the cone, and insulated from it, was wound a heating coil of known resistance for calibrating the receiver. This was done by noting the temperature rise (galvanometer deflections) with the electrical energy input. The receiver was then exposed to an electric furnace, which was heated to various temperatures from 500 to $1200^{\circ} \mathrm{C}$. and the corresponding galvanometer deflections were observed. He obtained a value of $\sigma=6.30$.

(b) Observations by Féry and Drecq. ${ }^{46}$-The work was undertaken anew by Féry and Drecq, ${ }^{46}$ the receiver being a cone of brass having an opening of $30^{\circ}$ placed within a large sphere of brass, which was' surmounted by a glass tube with a capillary I $\mathrm{mm}$ in diameter. The large brass sphere was filled with alcohol, the whole forming a thermometer in which I $\mathrm{mm}$ rise in height of the column in the capillary indicated a rise in temperature of $0^{\circ} .005$. Surrounding the outside of the brass case was a coil of wire through which an electric current was passed and the energy input noted to cause the same temperature as that produced by exposing the opening of the cone to the radiator. They found a mean value of $\sigma=6.5 \mathrm{I}$. This is the highest value yet reported. The relative values obtained with the instrument show a fair constancy over the whole temperature range which extended to the melting point of gold. However, the same is true of Valentiner's values obtained by the bolomteric method. This indicates that there is some constant factor, which is not eliminated and which causes the numerical value of $\sigma$ to be high or low. Various suggestions have been made as to the cause of their excessively large values. It appears that part of the difficulty lies in the unsymmetrical way in which the instrument is operated. It is calibrated by a heating coil which is in contact with the alcohol (or air, in the first case) and can warm the latter by conduction and by absorption of radiant energy. On the other hand, the incoming radiation must be transformed by absorption in the cone, and the effect produced reaches the alcohol principally by conduction. As a result of this type of calibration, the apparent value of the radiation constant is 
higher than the true value. The weak point is in not having the heating coil within the receiver, which should be constructed so that but little, if any, of the entering radiation, or the energy radiated from the heating coil, can escape through the opening in the receiver. This might easily have been done by forming the receiver into a double-coned receiver, such as was used by Puccianti. However, even with all these precautions, this type of receiver does not appear satisfactory.

A further determination of this constant was made by Féry and Drecq, ${ }^{57}$ in which the radiations from an electric furnace fell upon a strip of platinum (area 36 by 55 and $0.03 \mathrm{~mm}$ in thickness), blackened electrolytically with platinum black. The radiation measurements were made by sighting upon the front and the rear surfaces of the platinum strip by means of a Féry pyrometer, the angle of incidence being $48^{\circ}$. Their new value of the radiation constant is $\sigma=6.2$. The measurements upon the posterior surface lead to the value $\sigma=5.57$, which is said to correspond with the measurements on the anterior surface made with plane receivers. If we correct the latter value by 2 per cent for reflection we obtain the value $\sigma=5.68$, which is of the same magnitude as observed by the writer. This new determination of $\sigma$ by Féry and Drecq appears to have been made defective by their reduction of the original observations; for example, they claim that the coefficient of absorption of the receiver was only 0.82 to 0.84 , which seems impossible from numerous and diverse experiments on the diffuse reflecting power of platinum black made by others. Attention was called to this fact by Bauer, ${ }^{58}$ who places their value of $\sigma$ between 5. I and 5.8 , and, by making a correction of 2 per cent for reflection, deduced a value of $\sigma=5.68$. In all three methods the data are meager as to elimination of the various errors which may occur. For example, an error may arise in determining the power put into the platinum strip. Another important source of error lies in the manner of operation of the water-cooled shutter, which should be placed between the water-cooled diaphragm and the radiator.

(c) Observations of Bauer and Moulin.59-In order to obviate the difficulties encountered by Féry and Drecq ${ }^{57}$ in calibrating their conical-shaped receivers, Bauer and Moulin calibrated their receiver (which was a Féry pyrometer) by sighting it upon a strip of platinum which was heated to different temperatures by 
an electric current. In order to determine the amount of radiant energy falling upon the receiver it was necessary to eliminate the losses from the strip by conduction and convection. For this purpose the platinum strip was heated in air and in a vacuum, the power consumed being determined for a definite length of platinum, defined by potential terminals as used in the present paper. Having calibrated the pyrometer by noting the galvanometer deflections for the various amounts of energy put into the platinum strip, they sighted the pyrometer upon a black body heated to various temperatures and noted the galvanometer deflections. Their first announced value was $\sigma=6$.o. However, as in numerous other cases herein cited, they introduced errors in the final reduction of their data. They had observed the radiation emitted from the platinum strip at an angle of $13^{\circ}$ from the normal and applied a correction ${ }^{60}$ of about $\mathrm{I} 2$ per cent, which reduced their value to $\sigma=5 \cdot 3$. This correction is recognized to be much too large, ${ }^{58}$ so that their value of the radiation constant lies between $\sigma=5.3$ and 6.0, which indicates the close grouping of all the determinations about the value $\sigma=5.7$. They made no correction for atmospheric absorption which would increase their value from $\sigma=5.3$ to $\sigma=5.6$ or 5.7 . In a previous communication on the solar constant Bauer and Moulin (loc. cit., ${ }^{60}$ p. 1658), using an Ångström pyrheliometer, found the value $\sigma=5.7$.

(d) Observations of Puccianti. ${ }^{61}$ - In a continuation of his investigations Puccianti gives a determination in absolute measure of the radiation of a black body in which the temperature change is measured by means of a toluene thermometer, the bulb of which is formed into a hollow cone that is allowed to radiate to a blackbody receiver, which is at the temperature of liquid air. The measurement is made by compensating the heat lost by the thermometer by the application of an electric current.

The apparatus not being differential in construction, the temperature of the water bath had to be kept rigorously constant in order to have the meniscus of the thermometer move slowly and regularly. The response of the apparatus was, of course, slow and sluggish, which is a common property of this type of receiver (radiator), so that it required from four to eight minutes to obtain a measurement.

The same criticisms apply to this instrument that have been mentioned in the cruder form of thermometer used by Féry and Drecq. ${ }^{56}$ The energy for compensation is supplied by a heating 
coil which is in contact with the liquid (a good scheme in so far as it applies to heating the liquid) and on the side of the wall of the receiver opposite to that upon which the incoming radiations impinge. The arrangement is therefore unsymmetrical. The heat of compensation should have been supplied by a coil inserted within the receiver, provision being made that little or none could escape by reflection and by direct radiation through the opening. In this manner the condition of heat interchanges would have been the most closely fulfilled. In the instrument as used the opportunity for escape of energy seems greater, so that in compensation there is a tendency to produce a value which is higher than the true value for radiation unaccompanied by conduction. By placing the heating coil within the receiver and using a high temperature radiator, Puccianti's device should be applied in the manner recently used by Keene. ${ }^{62}$

Puccianti considered the precision of this method as high as that of the bolometric apparatus, but the sensitivity of the thermometric apparatus was very much inferior to the bolometer. Nevertheless, he seems to prefer the thermometric method in spite of its small sensitivity. He obtained a value of $6.00<\sigma<6.3$, and his intermediate value is $\sigma=6.15$.

(e) Observations of Keene. ${ }^{62}$-In the determination of the constant $\sigma$ by Keene, the radiator consisted of an electric furnace which could be heated to $1000^{\circ} \mathrm{C}$. The receiver consisted of a hollow, spherical, double-walled thermometer bulb provided with a small aperture in its side to admit the radiation to be measured. The space between the walls is filled with aniline, which served as thermometric substance, its expansion being observed in a capillary tube in the ususal way, I mm division $=0.0005^{\circ} \mathrm{C}$.

In order to eliminate the effect of the variation of room temperature, two such thermometers were used differentially, radiation being admitted into one of them, the differential effect giving a measure of the energy supply. The interior of the bulb receiving the radiation was provided with an electric heating coil for the purpose of calibration. The paper contains the derivation of an exact expression for the energy interchange between two radiating coaxial circular openings. For he found that the approximate formula, which is ordinarily used when the distance between the opening is large, was not accurate enough for his work. His value of the radiation constant is $\sigma=5.89$. 


\section{INDIRECT AND SUBSTITUTION METHODS}

(a) Observations of Shakespear. ${ }^{3}$-The value of the constant $\sigma$ is obtained by a method which is based upon the principle that a heated body in air, in surroundings at a lower temperature, loses heat $(a)$ by conduction, $(b)$ by convection, and $(c)$ by radiation. If the rate of heat loss by a body be observed in two cases, the only difference being that the emissivity of the radiating surfaces varies, other conditions remaining the same, it is quite correct to assume that the losses $(a)$ and $(b)$ will be the same and that the difference between the observed rate of loss of energy in the two cases is due only to the difference in the losses by radiation. If, now, these two different surfaces, at the temperature of boiling water, be exposed in turn to a radiomicrometer at the room temperature, we obtain the ratio of the rates of the energy radiated by the two surfaces.

In the experiments a plate of metal with a silvered surface was heated electrically to $100^{\circ} \mathrm{C}$, and close to it was another plate, blackened with soot, which was cooled with water. Between the plates was air at atmospheric pressure. Shakespear measured the energy input in order to maintain the plate at $100^{\circ}$ when (I) the surface of the plate was highly polished and (2) when it was blackened. He measured also the ratio of the emissivities of the plate under these two conditions, using a radiomicrometer for the purpose. From this he obtained a value, $\sigma^{\prime}$ in absolute units. $\mathrm{He}$ then compared the emissivity of the lampblack surface at $100^{\circ}$ with that of a black body at the same temperature by means of a radiomicrometer. From this latter comparison combined with the value of $\sigma^{\prime}$ he found a value of $\sigma=5.67$.

From this description it may be noticed that the essential parts of the method differ from that of Westphal ${ }^{65}$ in that the radiator was a flat metal plate which was used in air instead of a vacuum, and that the black body, with which the emissivity of the plate had to be measured, was separate from it; while in Westphal's instrument the black body was self-contained within the metal (in the form of a cylinder), of which the emissivity of the surface had to be measured.

(b) Observations of Todd. ${ }^{64}$-In his experiments on the thermal conductivity of gases Todd used a thin layer of air inclosed between two horizontal, parallel, good-conducting plates, which were maintained at different temperatures The colder plate, of course, receives heat by radiation and by conduction through the air from 
the hotter plate, which is above it. Communication from the surrounding air is shut off by an insulating ring, and the two plates being close together in comparison with their linear dimensions the convection currents are eliminated. He determined the energy lost by radiation by varying the distance $x$ between the two plates and noting the corresponding variation in the quantity $Q$ of heat passing from the upper to the lower plate. These values of $x$ and $Q$, when plotted, form a rectangular hyperbola and the horizontal asymptote gives the value $R$ of the radiation. The energy input was determined by a calorimetric method. In order to determine the constant $\sigma$, he had simply to find the ratio of emissivities of the blackened plate to that of a black body at the same temperature, for which purpose a radiomicrometer was employed. The value of this ratio and the constants obtained in the main part of his experiment enabled him to compute the radiation constant which he found to be $\sigma=5.48$.

This, like the preceding method, is likely to give a low value of the coefficient of total radiation owing to uncertainty of the exact temperature of the radiating surface of lampblack. A thin layer of soot is fairly efficient in its emission and absorption. But a thick layer of soot is quite nonconducting of heat, as was found by the writer ${ }^{1}$ in the measurements of diffuse reflection.

(c) Observations of Westphal. ${ }^{65}{ }^{66}$-An important determination of the coefficient of total radiation was made by Westphal. The experiment consisted in comparing the emissivity of a cylindrical block of copper, when it was highly polished and when it was blackened, with the emissivity of a black body at the same temperature. The novelty involved in the method is in having the black body contained within the cylinder. The copper cylinder was heated electrically, and, to reduce the energy losses by gaseous heat conduction, this copper cylinder was suspended in a glass flask, from which the air could be exhausted to I $\mathrm{mm}$ pressure. The outer surface of the cylinder was either highly polished to give it a low emissivity or painted with lampblack to give it a high emissivity. The end surfaces remained unchanged. The heat losses by conduction and convection were therefore the same throughout the experiment, and the difference in energy input, when the surface of the cylinder had a high emissivity and when it had a low emissivity, was a measure of the energy lost by radiation.

Using the surface of the cylindrical body when highly polished, Westphal proceeded to find the curve of energy input of the body 
as a function of the temperature between the temperatures 350 and $425^{\circ}$ absolute. Then the surface of the body was brought to a high emissivity by applying in succession different blackening materials, and the energy input was measured at different temperatures.

The emissivities of the surface and of the interior of the copper cylinder were compared by means of a thermopile. The numerous details need not be discussed. Suffice it to say, that the work appears to have been thoroughly done, and from the nature of the method it seems free from gross systematic errors. His mean value is $\sigma=5.54$.

He modified the apparatus, extending the observation over a wider range of temperature with a view to increasing the accuracy, and obtained the value $\sigma=5.57$. Although nothing further seems to have been published subsequently, Westphal obtained further measurements, which yielded the value $\sigma=5.67 .^{68}$

This is in excellent agreement with Shakespear's results, ${ }^{63}$ showing that the coefficient of radiation as determined by reliable methods is the order $\sigma=5 \cdot 7$.

As already noted in discussing Todd's data, it is uncertain whether in all cases the surface of a layer of lampblack soot has the temperature of the metal plate upon which it is deposited. Gerlach ${ }^{47}$ performed experiments which led him to question whether Westphal's results were not slightly low owing to the use of lampblack.

This and the preceding measurements of the coefficient of total radiation are excellent variations from the direct method. They are likely to give slightly low values, just as the thermometric methods, just described, give high values. Hence, these two methods serve the purpose of establishing upper and lower limits of the radiation constants.

(d) Deductions of Lewis and Adams. ${ }^{67}$ - In concluding the survey of what the writer considers the most reliable experimental determinations of the coefficient of total radiation, it is of interest to include in this paper a theoretical computation by Lewis and Adams based upon data on the elementary electric charge, $e$, the gas constant, $R$, and the Faraday equivalent, $F$. Their calculations lead to a value of $\sigma=5.7$.

The foregoing data are assembled in Table $\mathbf{I}$, which gives also the corrected values after making conservative corrections for atmospheric absorption, which important factor was in many cases neglected by experimenters. 
It is interesting to find that these data, which were obtained by widely different methods and which appear so discordant on first perusal of the original papers, are in excellent agreement. The various values range about the number, $\sigma=5.7$. In fact, twothirds of the total number (I2) of determinations are close to $\sigma=5.7$. The mean value of all the data which are free from obvious errors is $\sigma=5.72$ to 5.73 . If we neglected Todd's low value, determined from gas conduction experiments, and Puccianti's high value, which is, no doubt, too high, the mean value remains unchanged. As we shall see presently, experimental data on ionization potential, X-rays, and photoelectric work show that the value of the coefficient of total radiation is of the order $\sigma=5.7 \times \mathrm{IO}^{-5} \mathrm{erg}_{\mathrm{cm}}^{-2} \mathrm{sec}^{-1} \mathrm{deg}^{-4}$

TABLE 1.-Observed Value and the Most Probable Value of the Constant of Total Radiation after Correcting for Reflection, Atmospheric Absorption, etc.

\begin{tabular}{|c|c|c|c|c|}
\hline Observer & Date & $\sigma \times 10^{5}$ & $\begin{array}{c}\text { Probable } \\
\text { value of } \\
\sigma \times 10^{5}\end{array}$ & Method \\
\hline Kurlbaum... & 1898 & 5.45 & ? & Bolometer. \\
\hline Féry............. & 1909 & 6. 3 & ? & Thermometer. \\
\hline \multirow[t]{2}{*}{ Bauer and Moulin. } & 1909 & 5. 30 & 5.7 & Thermopile. \\
\hline & 1910 & 5.7 & 5.7 & Pyrheliometer. \\
\hline Todd......... & 1909 & 5.48 & 5. 48 & Gas-conduction experiments. \\
\hline Valentiner........ & 1910 & 5.58 & 5.68 to 5.75 & Bolometer. \\
\hline Fêry and Drecq... & 1911 & 6.51 & ? & Thermometer. \\
\hline Do........... & 1912 & 6.2 & 5.68 & Calibrated pyrometer. \\
\hline Do......... & 1912 & 5. 57 & ...... & \\
\hline Shakespear....... & 1912 & 5. 67 & 5.67 & Ratio of emissivities, metal; black body. \\
\hline \multirow[t]{2}{*}{ Gerlach......... } & 1916 & 5.85 & ….... & Modified Ångström pyrbeliometer. \\
\hline & 1920 & 5. 80 & 5. 80 & \\
\hline \multirow[t]{2}{*}{ Puccianti.... } & 1912 & 5.96 & 5. 96 & Bolometer. \\
\hline & …... & 6. 15 & ? & Thermometer. \\
\hline Westphal.......... & 1916 & 5.67 & 5.67 & Ratio of emissivities, metal; black body. \\
\hline Keene. . ............ & 1913 & 5. 89 & 5. 89 & Thermometer. \\
\hline Coblentz........... & 1915 & 5. 72 & 5.72 & Modified Ångström pyrheliometer. \\
\hline Kahanowicz....... & 1917 & 5. 61 & 5.69 to 5.73 & Modified Ångström pyrbeliometer. \\
\hline Foote................ & 1918 & 5.70 & 5. 70 & Marvin pyrheliometer. \\
\hline
\end{tabular}

\section{DISCUSSION OF VARIOUS DETERMINATIONS OF THE CONSTANT OF SPECTRAL RADIATION}

Planck's ${ }^{18}$ equation $E_{\lambda}=c_{1} \lambda^{-5}\left(e^{\mathrm{c} / \lambda T}-\mathrm{I}\right)^{-1}$ is, no doubt, the closest representation yet formulated of the observed energy distribution in the spectrum of a black body. The constant $C$ (often written in the more cumbersome form $C_{2}$ ) determines to a great extent the slope of the isothermal spectral energy curve. In the 
spectral region, free from atmospheric absorption, to $6 \mu$, the observed and the computed curves obtained by the writer, ${ }^{76}$ are in agreement to within the errors of observation, viz, 0.5 to I per cent.

Rubens and Kurlbaum 77 have made isochromatic observations using the residual rays of fluorite in the spectral region of $24 \mu$ and $52 \mu$. Their data are also in exact agreement with those computed by the Planck equation. From these data it appears that the Planck equation may be considered as representing, within the errors of observation, the energy distribution of a black body in the spectrum extending from $0.5 \mu$ to $50 \mu$.

The Planck formula is based on theoretical considerations, and after almost two decades of discussion it remains unchanged. Recently, Nernst and Wulf ${ }^{78}$ have arbitrarily modified the coefficient in the above equation, changing $C_{1}$ to $C_{1}(\mathrm{I}+a)$, where $a$ is a variable. The whole procedure is based upon the assumption that the numerical value of the constant is $C=14300$, as observed from isochromatic observations. Hence, in view of the fact that the (older) values of $C$, obtained from isothermals, are somewhat higher, they must be reduced by a factor $(I-a)$, depending upon the temperature of the radiator. They point out explicitly that the whole procedure depends upon the truth or falsity of the value of $C=\mathrm{I} 4300$; or, rather, as will be seen presently, upon the truth or falsity of the older values of $C=14400$ (about) obtained from isothermal measurements. Their deductions lead to a value of $\sigma=6.04$, which from a consideration of the whole subject, on a subsequent page, appears to be much higher than the true value. Until we have more reliable experimental data, using isothermais, it does not appear necessary to consider a modification of the Planck equation.

In spite of all that has been published on the partition of energy in the spectrum of a black body, there are but few data at hand which are more than qualitative in value.

To the writer it seems that all these early data should be considered from the standpoint of historical interest, since it seems impossible to give them much weight in connection with the results obtainable at the present day.

(a) Observations of Paschen. ${ }^{60},{ }^{70}$-The pioneering work in spectral radiation measurements and constants was inaugerated by Paschen, ${ }^{69}$ who observed an extensive series of spectral energy curves at temperatures ranging from roo to $450^{\circ} \mathrm{C}$, using six different kinds of bolometers covered with different kinds of ab- 
sorbing material-for example, lampblack and platinum black or copper oxide-also having the bolometers in the focus of a hemispherical mirror. The radiators were heated by means of boiling water, aniline, sulphur, etc. The mean value of all his observations, which are in close agreement, was $A=\lambda_{\mathrm{m}} T=289 \mathrm{I}$ and $C=$ 14352. He continued the work at temperatures ranging from 400 to $1050^{\circ} \mathrm{C}$ using a large porcelain radiator. He used also metal cups of copper or platinum blackened with oxides of copper or iron, and heated within this porcelain radiator, making in all about a dozen different arrangements of the radiators The bolometer was covered with platinum black and was situated in the focus of a hemispherical mirror to "blacken" it. The mean of the new series was $A=2907$, with a probable error of $\pm I 6$.

In a further investigation Paschen ${ }^{70}$ undertook the work anew, after redetermining the reflecting power of silver and the refractive indices of fluorite. He used a porcelain tube radiator, also three other radiators, which he blackened, as in the preceding research. He took the wise precaution to project an image of the radiating wall of the black body upon the spectrometer slit in order to avoid possible radiations from the side walls and diaphragms falling upon the prism and bolometer. Complete corrections for the selective reflection of the silver mirrors, and also for the loss by reflection from the prism, were made He then found that his observations fitted neither the Wien nor the Planck equation, the values on the long wave-length side of the energy curves falling between the two theoretical curves He found that if (for reasons he himself could not explain, loc. cit., p. 295) he multiplied his observations by factors varying from I.O2 at $2.91 \mu$ to $\mathrm{I} .195$ at $8.25 \mu$, etc., the observed energy curve would fit the Planck equation and fulfilled better the condition of congruence. Upon this basis he obtained a value of $A=2921$ for his newest data. He then applied factors to some of his previous data, thus making them agree better with the Planck equation, and the value of $A$ was increased from 289I to 29I 5, or about 0.87 per cent From this it appears that, if he had not multiplied his observations by these arbitrary factors, his latest results would have been about 0.87 per cent lower or $A=2894$, which is practically the same as the value previously obtained.

The writer ${ }^{30,}{ }^{76}$ has obtained an estimate of the correction to Paschen's values, and the conclusion arrived at (loc. cit. ${ }^{76}$ p. 468 ) is that Paschen's recent determination is of the order $A=2894$. This is close to the earlier determination, $A=289 \mathrm{I}$, which is prob- 
ably more reliable as regards the temperature scale. In other words, Paschen's original data fall within the range of the recent and more accurately determined values, being of the order $C=14360$.

(b) Observations of Lummer and Pringsheim. .11,73,83_Their spectral radiation measurements were made on porcelain tube radiators, described in the first part of this paper. The radiator was placed directly in front of the spectrometer slit. This reduces the length of air path, and hence the absorption; but there is uncertainty in keeping the alignment, especially since in the early designs no attempt was made to prevent the tube from sagging.

As is true of all the older measurements on radiators, operated, above $1200^{\circ} \mathrm{C}$, the temperature scale is defective (too high)giving values of $C$, which are too high.

The values of the constants published by Lummer and Pringsheim ${ }^{71}$ require a treatment similar to that just given to Paschen's data. They used the earlier indices of refraction of fluorite, published by Paschen ${ }^{10}$ in 1894 , which are in error in wave length by $0.02 \mu$ for the region of I to $2.5 \mu$. Fortunately, most of their values of $\lambda_{m}$ are greater than $2.5 \mu$, and no correction is required.

In their first investigation a series of four spectral energy curves, observed at temperatures of 837 to $1416^{\circ} \mathrm{Abs}$, gave a value of $A=2879^{\circ}$.

For a second series of measurements, they inclosed the spectrometer in order to dry the air. A series of five spectral energy curves observed between the temperatures of 814 and $1426^{\circ} \mathrm{Abs}$ gave a value of $A=2876$. These two values are in close agreement with Paschen's determinations made at that time. They found that their data did not fit the Wien equation, and this, no doubt, gave impetus to the formulation of the Planck equation. Suffice it to say that their data, obtained up to this time, if reduced on the basis of the Planck factor $\alpha=4.965 \mathrm{I}$, leads to a value of $\mathrm{C}=14290$.

In a subsequent investigation ${ }^{73}$ the radiator was heated to a much higher temperature, to $1646^{\circ}$ Abs. A series of eight isothermal spectral energy curves gave a value of $A=2940$ and $C=$ 1459o. In view of the fact that a correction of about $0.02 \mu$ must be made for the calibration at I to $2.5 \mu$, this would reduce the value of $C$ by 2 per cent or $C=143$ Io. Although the apparatus was inclosed in order to remove the $\mathrm{CO}_{2}$ and water vapor, the energy curves are appreciably affected by atmospheric absorption. 
As in previous work, their temperature scale, above $1000^{\circ} \mathrm{C}$, was obtained by extrapolation. Just how much the thermocouple calibration may be in error is not recorded. In a subsequent paper ${ }^{83}$ they revised the temperature scale used in the previous test ${ }^{24}$ of the Stefan-Boltzmann, fourth-power law. The revised temperatures are 10 to $12^{\circ}$ lower, and, at the highest temperatures, they are 20 to $25^{\circ}$ lower than previously used. Whether any temperature correction of this magnitude must be made to the spectral radiation data is not stated; though the researches on the gas thermometer by Holborn and Day ${ }^{84}$ were then in progress. Suffice it to say that although their later value of $A=2940$ is the one frequently quoted in books, none of the subsequent investigators have found a value of $A$, which is within I 5 per cent as high as is this one.

From the foregoing consideration of the data obtained by Lummer and Pringsheim it appears conservative to place their value at $C=\mathrm{I} 4300$.

(c) Observations of Warburg and Collaborators. ${ }^{86}$ to 95 -During the past 20 years the determination of the constants of radiation and their application to the temperature scale has been relentlessly pursued by the Phys. Tech. Reichsanstalt, ${ }^{83}$ at Berlin.

During the past ro years these investigations have been pursued by Warburg and his collaborators. They used fluorite and quartz prisms and vacuum radiators. The sodium line was used as a zero setting of the spectrometer. The radiometer was a vacuum bolometer, which was operated by a null method. In this manner the galvanometer acted merely as an inclicator. The temperature fixed points were the melting point of gold and some higher temperature, for example, melting point of palladium.

In their first communication, ${ }^{86,87}$ they reported a value of $C=14570$ on the basis that the melting point of palladium is $\mathrm{I} 549^{\circ} \mathrm{C}$. On the other hand, if the higher temperature was determined radiometrically, by extrapolation from the gold point, using the Stefan-Boltzmann law, then the value of $C$ was found to be smaller. Hence, they rightly questioned the gas-thermometer scale and proceeded to make their investigations by using the radiation laws to establish their scale of temperatures, thus avoiding the scale as transferred from the gas thermometer by means of thermocouples. They retained only one temperature fixed point, viz, gold at $1064^{\circ}$ (later $\left.1063^{\circ}\right)$. The higher temperatures $\left(\mathrm{I}_{400^{\circ}}\right)$ were determined radiometrically. For this purpose they observed the position, $\lambda_{m}$, of the maximum emission $\mathrm{E}_{\mathrm{m}}$, of the isothermal spectral energy curve. 
Using Paschen's refractive indices of fluorite and Carvallo's ${ }^{99}$ indices of quartz, in their next communication, ${ }^{88}$ they report values which varied from $C=I 4200$ to 14600 .

Using improved methods for adjusting the sodium lines on the bolometer and making further provision so that radiation emanating from only the central diaphragm of the radiator was incident upon the bolometer, in the next report ${ }^{89}$ the fluorite prism gave values ranging from $C=\mathrm{I} 4300$ to $\mathrm{I} 4600$ and it was discarded. A quartz prism gave a value of $C=I 4360$.

In a very complete investigation ${ }^{90,91}$ they repeated the previous work. Using a quartz prism, the values obtained are $C=\mathrm{I} 3$ $270 \pm 40$ and $A=2894 \pm 8$, for the temperature interval of $\mathrm{I} 337$ and $2238^{\circ}$ Abs.

The next step was to cut a prism out of a block of quartz, of which the absorptivity had been determined previously. With this and other improvements, including different radiators, a value of $C=\mathrm{I} 4250$ was obtained ${ }^{93},{ }^{94}$ from the temperature scale based on the Stefan-Boltzmann law of total radiation and a value of $C=\mathrm{I} 4300$ or I 4400 was obtained by using the Wien displacement law to establish the temperature. The uncertainty in the value of $C=\mathrm{I} 4300$ or I 4400 is owing to the uncertainty in their calibration curve (refractive indices) of the quartz prism.

The present status is the adoption ${ }^{95}$ of the value of $C=\mathrm{I} 4300$ and the melting point of palladium $=1557^{\circ}$ C. Subsequent investigations ${ }^{96},{ }^{97}$ appear to be made on this basis. There is an uncertainty of perhaps $\mathrm{I}^{\circ}$ in the temperature scale at the melting point of palladium, ${ }^{98}$ and, in view of the great variations in the various determinations of $C$, it was perhaps a wise decision for Warburg to adopt the rounded number $C=I 4300$ micron degrees, for the spectral radiation constant; though, as we shall see presently, theory and other experimental data would place the value somewhat higher.

(d) Observations of Coblentz.30, 76, 4-In this investigation the spectrum was produced by means of a mirror spectrometer and a perfectly clear fluorite prism. In the first work an air bolometer, and later a vacuum bolometer was used for measuring the partition of energy in the spectrum. The radiator was a porcelain tube, wound with platinum ribbon, through which electric current was passed. It was operated at temperatures ranging from $45^{\circ}$

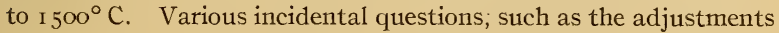
of the optical parts of the apparatus, the temperature uniformity 
and control of radiator, the water-cooled shutters, the temperature scale, the method of reduction of the observations to the normal spectrum, the proper formulas for computing the numerical constants, etc., were investigated.

The first paper ${ }^{30}$ contains also data on various subsidiary problems, such as (I) the variation of the reflecting power of silver with angle of incidence and with wave length, (2) the variation of reflecting power of fluorite with angle of incidence and with wave length (refractive index), and (3) data for reducing the observations from prismatic to normal spectrum.

From the very beginning of this investigation on black-body radiation it was found that the Wien equation did not fit the spectral energy curves. The assumption was, therefore, tentatively made that the observed curves fit the Planck equation; and, at the completion of the investigation, this was found to be true for about 75 per cent of all the observed curves. This conclusion was based upon the uniformity of the values of $\lambda_{m}$, which resulted from computation (by the method of equal ordinates $E_{\lambda_{1}}=E_{\lambda_{2}}$ ) of the values of $\lambda_{1}$ and $\lambda_{2}$ which were taken far apart, and also close together on the observed isothermal spectral energy curve.

The observations were made in the winter, when the humidity was low, and the investigation extended over four winter seasons. An attempt was made to obtain a great many isothermal spectral energy curves, so as to avoid the personal bias which can enter the working over of a few curves. It now seems that this was probably a mistake; for no attempt could be made to correct the observations for small changes in temperature of the radiator and small variations in sensitivity of the vacuum bolometer.

In the meantime, owing to impairment of eyesight, the reduction of the data had to be intrusted to others who were not familiar with the work. The first calculation of the data gave a value of about $C=\mathrm{I} 4$ 350. But doubts arose concerning the calibration curve of the prism. A new calibration curve was worked out, using Paschen's ${ }^{11}$ refractive indices (uncorrected for temperature) and the data recalculated and published as being $C=14456$.

Data were obtained also with a fluorite prism which was full of cleavage planes. This produced much scattered radiation, which distorted the energy curves at $4 \mu$ to $5 \mu$. These data were, therefore, not used in the final calculations. (This explains the queries by Nernst and Wulf. ${ }^{78}$ ) 
In the meantime Paschen ${ }^{12}$ published further data on the dispersion of fluorite, which indicated that the calibration curve, and hence the value of $C=14456$, was wrong.

In the earlier work the temperature scale was also in doubt. The last series (1912) was not observed at temperatures much above $1200^{\circ} \mathrm{C}$ and hence is quite free from doubts about the temperature scale.

The second paper ${ }^{76}$ on this subject, therefore, dealt with a recalculation of these data, using a revised calibration curve. The mean value of the spectral radiation constant, based on 93 spectral energy curves (series of 1912 ) is $C=14353$. If the corrections to the temperature scale (mentioned in the previous paper) are applied, the value is $C=14362$. A further correction $(=+7)$ is necessary, because in the second term of the equation used for calculating the data the value $C=\mathrm{I} 4300$ instead of $C=\mathrm{I} 4350$ was employed. Hence, the final corrected value, as published in the second paper, was $C=14369$ and $A=2894$ micron degrees.

In order to obtain a check on the methods of calculation of the constant a least square reduction of the first isothermal curve of the series of 1912 was undertaken by Roeser. ${ }^{81}$ He obtained a value of $C=14342$, which is in agreement with the value computed by the method of equal ordinates, viz, $C=\mathbf{1} 4339$.

Recently a further examination ${ }^{4}$ was made of the accuracy of the factors used in converting the previously observed ${ }^{30}$ prismatic spectral-energy data into the normal energy distribution. The graphical methods previously employed were checked, and similar factors were obtained by computation, using the first differential of the dispersion formula, which best represents the observed refractive indices of fluorite. ${ }^{101}$ These refractive indices were obtained from consideration of all the available data, which in the region of $\mathrm{I}$ to $2 \mu$ are represented by the curve published by Langley and Abbot. ${ }^{8}$ The best dispersion formula is that of Paschen. ${ }^{101}$ However, owing to incompleteness of the formula, the graphical method was found to be just as accurate as was the method of computation.

The conclusion ${ }^{4}$ arrived at was that the spectral radiation constant, $C=14353$ micron degrees, determined some years ago ${ }^{76}$ remains unchanged. However, at that writing ${ }^{4}$ there was some doubt as to whether some of the corrections then applied should have been made, giving a value of $C=I 4369$; that is, the mean value might be $C=\mathrm{I} 4366$. 
Rather curiously and unfortunately, in all these inquiries into the small errors that eight years ago were considered negligible the one concerning the zero setting has remained unconsidered until now. The calculation of the calibration curve was based on the sodium lines, $\lambda=0.5893 \mu$ for a reference point. Subsequently the writer adopted the then novel procedure of using the yellow helium line, $\lambda=0.5^{8758} \mu$, instead of the sodium lines for adjusting the zero setting of the bolometer. For this purpose the refractive index $n=\mathrm{I} .43390$ was adopted. Subsequently Paschen ${ }^{12}$ published the value of $n=1.433907$ ( $17 .{ }^{\circ}$ C) for the refractive index of the helium line, and $n=\mathrm{I} .433866$ for the sodium lines. He observed a difference of $12^{\prime \prime}$ in the minimum deviation settings of the sodium and the helium lines.

On the basis of the new value of the refractive index of fluorite for the yellow helium line, $n=\mathrm{I} .433877\left(\right.$ at $\left.20^{\circ} \mathrm{C}\right)$, there is a difference of $6^{\prime \prime}$ between the newly computed (zero) minimum deviation setting of the spectrometer circle and the setting used in this investigation on the basis of $n=\mathrm{I} .43390$. As a result, the average values of $\lambda_{m}$, in terms of the spectrometer circle, must be reduced by $6^{\prime \prime}$. Since the wave lengths, $\lambda_{m}$, occur between $2 \mu$ and $3 \mu$ (and the majority at about $2.2 \mu$ ) the $6^{\prime \prime}$ are equivalent to $0.003 \mu$ to $0.004 \mu$ in this part of the spectrum. This amounts to a reduction of the previously published value of the constant $C=14369$ by 0.3 to 0.4 per cent, giving a value of $C=143$ I I to I 4326 .

As already stated, the second paper ${ }^{76}$ was the result primarily of a revision of the calibration curve of the fluorite prism used; and it is unfortunate that at that time the above application of the temperature coefficient of the refractive index of the helium line was overlooked.

The various determinations of the constant of spectral radiation, $C$, are assembled in Table 2 . The sixth column gives the probable value, as determined from consideration of the data in the text. The mean value is $C=14320$ micron degrees. The latest and most reliable determinations of the national laboratories are close to this value. Unfortunately, perhaps, this average is so close to the theoretical value arrived at from consideration of photo-electrical and similarly related phenomena that experimenters may consider their task finished, instead of just begun. 
TABLE 2.-Observed Value and the Probable Value of the Constant $\mathrm{C}$ of Spectral Radiation

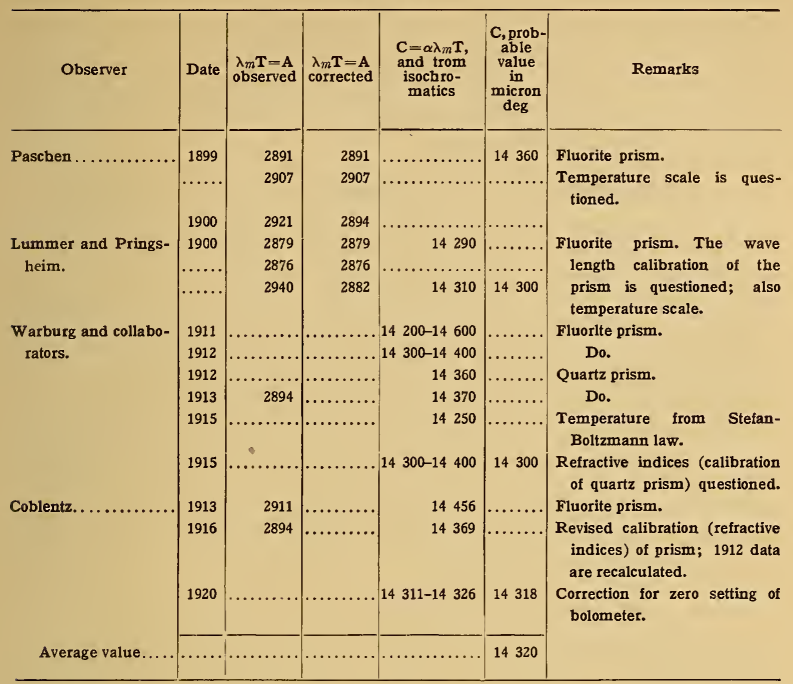

\section{VERIFICATION OF THE LAWS OF RADIATION}

In the foregoing pages an inquiry was made into the instruments and methods used in, and the numerical values of, various determinations of the constants of radiation.

The various methods are classified, and a brief description is given of each research. An attempt is made to indicate the good and the defective features in each research. This represents not only the writer's opinions, but also those of other experimenters.

it is shown that the great variation in the various determinations of the numerical values of the constants, especially the constant of total radiation, is owing mainly to the fact that, in the original papers, no corrections were made for atmosphere absorption of radiation in its passage from the radiator to the receiver.

In this paper conservative corrections for atmospheric absorption are applied to the various determinations, to which such corrections had not been made. As a result, instead of wide variations in the various determinations, which are free from other obvious defects, there is a remarkably close agreement among the 
various numerical values. While it can not be said that the true numerical values are exactly as here recorded, obviously the time is past when the value of the constants of radiation are swayed by a single, and perhaps novel, method of research. The best that an experimenter should expect is that his own little contribution to the subject may have sufficient merit to go into the melting pot with the other determinations.

\section{THE FORMULA AND THE COEFFICIENT OF TOTAL RADIATION}

In the foregoing review the data are assembled and the evidence weighed pro and con. It is shown from various experiments that, beyond all reasonable doubt, the total radiation emitted from a uniformly heated inclosure is proportional to the fourth power of the absolute temperature-the so-called Stefan-Boltzmann law. Furthermore, the tabulated data show that the numerical values of the majority of the various determinations of the coefficient $\sigma$, which enters into the mathematical formula of total radiation, range about the value, $\sigma=5.7 \times \mathrm{IO}^{-5} \mathrm{erg} \mathrm{cm}^{-2} \mathrm{sec}^{-1} \mathrm{deg}^{-4}$ The average of $\mathrm{I} 2$ of the most reliable determinations is $\sigma=5.72$ to $5.73 \times \mathrm{IO}^{-5} \mathrm{erg} \mathrm{cm}^{-2} \mathrm{sec}^{-1} \mathrm{deg} .^{-4}$

\section{THE FORMULA AND THE CONSTANT OF SPECTRAL RADIATION}

Experimental evidence is cited showing that throughout the spectrum from $0.5 \mu$ to $50 \mu$ Planck's formula fits the observed spectral-energy distribution more closely than any other equation yet proposed. This formula is based upon theoretical principles, and after two decades of discussion it remains unchanged.

The constant $C$, which determines the shape of the spectral energy curve, has been the subject of numerous investigations. The numerical value of $C$ has fluctuated greatly in the various determinations. In the foregoing pages it is shown that this is owing to experimental difficulties, such as, for example, lack of precise knowledge of the temperature scale and of the refractive indices of the prisms used. The tabulated data show that the various determinations of the constant of spectral radiation are of the order of $C=\mathrm{I} 4300$ to $1435^{\circ}$ with a mean value of $C=$ I4 320 micron degrees.

\section{CONFIRMATORY EVIDENCE}

One of the most interesting phases of the inquiry into the laws and constants of radiation is the confirmatory data which one obtains from a consideration of the interrelated phenomena of 
atomic structure, of $\mathrm{X}$ rays, of ionization and resonance potential, and of photo-electrical action. From these data, as well as from the foregoing data on the two constants of radiation, one can compute the value of Planck's element of action, $h$. This gives seven independent methods of determining the universal constant, $h$. Or, from any one of four of these methods one can calculate ${ }^{103}, 104,105$, the radiation constants, and it seems truly remarkable how close is the agreement with the observed values.

For example, the writer's ${ }^{4}$ value of the coefficient of total radiation, discussed on a preceding page, is $\sigma=(5.72 \pm 0.012) \times$ $\mathrm{xO}^{-5} \mathrm{erg} \mathrm{cm}^{-2} \mathrm{sec}^{-1} \mathrm{deg} .^{-4}$ This indicates ${ }^{105}$ a value of $C=\mathrm{I} 4320$ micron degrees and a value of $h=6.55 \times 1 \mathrm{I}^{-27} \mathrm{erg} \mathrm{sec}$. The value of $h$, determined by Blake and Duane, ${ }^{102}$ by $\mathrm{X}$ rays, is $h=6.555 \times$ $\mathrm{IO}^{-27}$ erg sec., or an indicated value of $C=\mathrm{I} 4330$ micron degrees, which is close to experimental determinations of this constant. (See Table 2.)

Again, starting with Warburg's value of $C=\mathrm{I} 4300$, the corresponding value of the coefficient of total radiation is $\sigma=5.74$, which is the higher estimated limit of the average of 12 different determinations of this constant, see Table $\mathrm{I}$. Hennig, ${ }^{103}$ on the basis of Sommerfeld's theory, the measurement of spectral lines and the value of the electron, obtains $C=\mathrm{I} 432 \mathrm{O}$ and $\sigma=5.7 \mathrm{I} 7$.

In summing up the evidence, it is of interest to include Birge's ${ }^{104}$ comprehensive and exact calculations of the constant $h$. In these calculations he, of course, assumes the truth of; ( $I$ ) Lewis and Adams's ${ }^{67}$ theory of ultimate rational units; (2) of the relation between $C, \sigma$, and $h$, as given by Planck's radiation formula; (3) of the quantum relation as applied to X-ray data; ${ }^{102}$ (4) of Einstein's photo-electric equation; (5) of Bohr's theory of atomic structure; and (6) of the quantum relation as applied to ionization and resonance potentials.

In this manner he obtains seven separate calculations of Planck's constant of action, $h$, the mean value of which, as shown in Table 3 , is $h=6.5543 \times \mathrm{IO}^{-27} \mathrm{erg} \mathrm{sec}$.

This is close to the average of the value of $h$, which results from consideration of the two radiation constants.

From this calculation and intercomparison by Birge ${ }^{104}$ of the data on $C, \sigma$, and $h$, as determined by thermal radiometric, photoelectric, $\mathrm{X}$ rays, and ionization potential measurements, it appears that the value of $h$, computed from radiometric data, compares very favorably with that obtained by more direct measurement. In other words, it appears to prove the validity of laws of 
radiation and to establish the level of the numerical values of the constants entering therein.

TABLE 3.-Birge's ${ }^{101}$ Calculation of Planck's Universal Constant $h$ by Various Methods

\begin{tabular}{|c|c|c|}
\hline Value of $h$ & Method & Kemarks \\
\hline $6.551 \pm 0.009 \ldots$ & $\sigma=5.72 \ldots \ldots \ldots \ldots \ldots \ldots \ldots \ldots \ldots$ & Total radiation. \\
\hline $6.557 \pm 0.013 \ldots$ & $\mathrm{C}=14330 \ldots \ldots \ldots$ & Spectral radiation. \\
\hline $6.542 \pm 0.011 \ldots$ & Rydberg constant ........ & Bohr's theory of atomic structure. \\
\hline $6.578 \pm 0.026 \ldots$ & Photo-electric equations... & Einstein's equations. \\
\hline $6.555 \pm 0.009 .$. & $\mathrm{X}$ rays ..... & Quantum reiation. \\
\hline $6.560 \pm 0.014 \ldots$ & Uitimate rational units ............... & Theory of Lewis and Adams. \\
\hline $6.579 \pm 0.021$ & Ionization potential ........ & \\
\hline
\end{tabular}

Mean value $h=6.5543 \pm 0.0025$.

The outstanding disagreement between all the observed and computed data appears to be of the order of $x$ to 3 parts in 1000 , whatever the method of experimentation. This is a very close agreement, considering the variety of the data and the difficulties involved in making the experiments, which seems to indicate something more than a fortuitous relation between properties of matter.

In conclusion it may be added that, to a close approximation, we have the following constants:

$$
\begin{aligned}
& A=\lambda_{\mathrm{m}} \mathrm{T}=2885 \text { micron degrees. } \\
& C=\mathrm{r} 432 \mathrm{O} \text { micron degrees. } \\
& \sigma=5.72 \times \mathrm{IO}^{-5} \mathrm{erg} \mathrm{cm}^{-2} \mathrm{sec}^{-1} \mathrm{deg} .^{-4} \\
& h=6.554 \times 10^{-27} \mathrm{erg} \mathrm{sec} \text {. }
\end{aligned}
$$

\section{BIBLIOGRAPHY}

${ }^{1}$ Coblentz, B. S. Bul., 9, p. 283; I9I3 (diffuse reflection).

${ }^{2}$ Coblentz, B.S. Bul., 11, p. 47 I; I 914 (optical constants of quartz).

${ }^{3}$ Coblentz and Fmerson, B. S. Bul. 12, p. 503; I916 (radiation in absolute value; atınospheric absorption).

${ }^{4}$ Coblentz, B. S. Bul., 15, j. 529; I920 (constants of radiation; atmospheric absorption).

${ }^{5}$ Warburg and Müller, Ann. der Phys. (4) 48, p. 4ro; I9I5 (constants of spectral radiation; absorption of yuartz).

${ }^{6}$ Gerlach, Ann. der Phys. (4) 50, p. 233; I9I6 (atmospheric absorption).

7 Warbürg and Muller, Zs. für Instr., 35, p. ro3; 1915.

${ }^{8}$ Annals Astrophys. Obs. Smithsonian Institution 1, p. 222, Plate XXVI B; 1902.

${ }^{9}$ Paschen, Ann. der Phys., (3) 53, p. 334; 1894 (refractive indices).

${ }^{10}$ Paschen, Ann. der Phys., (3) 56, p. $762 ; 1896$.

${ }_{11}$ Paschen, Ann. der Phys., (4) 4, p. 302 ; 1901.

12 Paschen, Ann. der Phys., (4) 41, p. p. 670; 1913. 
${ }^{13}$ Micheli, Ann. der Phys., (4) 7, p. 772; I902 (tempcrature coefficients of refraction).

${ }^{14}$ Liebreich, Verh. Phys. Gesell., 13, p. I; IgI I (temperature coefficients of refraction).

${ }^{15}$ Coblentz, B. S. Bul., 12, p. 553; I9r6 (constant of total radiation).

16 Stefan, Sitzungsber, d. K. Gesellsch., d. Wissensch. zu Wien (2) 79, p. 39 ; 1879.

17 Boltzmann, Ann. d. Phys., (3) 22, pp. 31 and 29r; r884.

18 Planck, Vorlesungen über Wärmestrahlung.

19 Draper, Amer. Jour. Sci. (2) 4, 1847, and Collected Papers.

${ }^{20}$ Kirchhoff, Pogg. Ann. d. Phys., 109, p. 275 ; 1860.

${ }^{21}$ Christiansen, Ann. d. Phys. (3) 21, p. $364 ; 1884$.

22 St. John, Ann. d. Phys. (3) 56, p. $433 ; 1895$.

${ }^{23}$ Wien and Luminer, Ann. d. Phys. (3) 56, p. $45 \mathrm{r} ; \mathrm{r} 895$.

${ }^{24}$ Lummer and Pringsheim, Ann. der Phys. (3) 63, p. 395; I897; (4) 3, p. I59, I9co.

${ }^{25}$ Schneebeli, Ann. d. Phys. (3) 22, p. 430; 1884.

26 Wilson, Astrophys. Jour., 10, p. 80; 1899.

${ }^{27}$ Valentiner, Ann. der Phys. (4) 31, p. 272 ; 19 го.

${ }^{28}$ Lummer and Pringsheim, Verh. d. Deutsch. Phys. Gesell., 1, pp. 33 and 2 I $5 ;$; 899.

${ }^{29}$ Coblentz, Carnegie Inst. of Washington, Publ. No. 65, pp. 77 and 80,1906 , and Pub. No. 97, p. 18, 1908.

${ }^{30}$ Coblentz, B. S. Bul., 10, p. I; I913 (constant of spectral radiation).

31 Waidner and Burgess, B. S. Bul., 3, p. $163 ; 1907$.

${ }^{32}$ Coblentz, B. S. Bul., 7, p. I69; I908 (emission spectra).

${ }^{33}$ Coblentz, B. S. Bul., 9, p. I06; 1912 (selective emission).

${ }^{34}$ Lehnebach, Pogg. Ann. d. Phys., 151, p. 96, 1873.

${ }^{35}$ Christiansen, Ann. d. Phys. (3) 19, p. 267 ; $188_{3}$.

${ }^{36}$ Kurlbaum, Ann. d. Phys. (3) 65, p. 746 ; 1898.

37 Kurlbaum, Verh. d. D. Phys. Gesell., 14, p. 576; I912.

${ }^{38}$ Valentiner, Ann. der Phys. (4) 39, p. 489, 1912; 41, p. 1059, 1913.

${ }^{39}$ Coblentz, B. S. Bul., 14, p. 532; I918 (instruments and methods of radiometry).

${ }^{40}$ Gerlach, Ann. der Phys. (4) 41, p. 99 ; I9I3.

${ }^{41}$ Callendar, Proc. Roy. Soc., Iondon, 23, p. I; I9ı.

42 Gerlach, Ann. der Phys. (4) 38, p. I; I9I2 (constant of total radiation).

43 Ångström, Phys. Rev., 1, p. 365; r893. Ann. der. Phys. (3), 67, p. 633; 1899 (pyrheliometer).

${ }^{44}$ Gerlach, Phys. Zs., I7, p. 150; 1916.

45 Paschen, Ann. der Phys., (4) 38, p. 30; I9I2.

46 Gerlach, Ann. der Phys. (4) 40, p. 70г, I9г3; 41, p. 99, I9I3; 42, pp. I163, I 167 , I913.

${ }^{47}$ Gerlach, Ann. der Phys. (4), 50, p. 245, I916.

48 Gerlach, Ann. der Phys., (4) 50, p. 259, I9I6 (constant of total radiation).

${ }^{49}$ Coblentz, B. S. Bul., 9, p. 40; I 1 I I (bolometers, hemispherical mirrors).

${ }^{50}$ Coblentz, B. S. Bul., 11, p. I 57, I9I4 (thermopiles).

${ }^{51}$ Coblentz, B. S. Bul., 13, p. 423 , I9r6 (ironclad galvanometers)

52 Christiansen, Wied. Ann. der Phys., 19, p. $267,188_{3}$ (formulas).

${ }_{53}$ Puccianti, Nuovo Cimento (6) 4, p. 3I; I9I2.

${ }^{54}$ Kahanowicz, Nuovo Cimento (6) 13, p. I42, I9I7.

${ }^{55}$ Féry, Compt. Rendus, 148, p. 915 , 1909.

56 Féry and Drecq, Jour. de Phys. (5), 1, p. 55 I, I9I I

${ }^{57}$ Féry and Drecq, Compt. Rend., 155, p. 1239, I912.

58 Bauer, Soc. Franç. de Phys., Procès Verbaux, No. 4r, I9I3.

${ }^{59}$ Bauer and Moulin, Compt. Rend., 149, p. 988, r909; Bull., Séancas Soc. Fr. de Phys., p. $5^{8,}$ igro.

${ }_{60}$ Bauer and Moulin, Compt. Rend., 150, p. I67, I9Io. 
${ }^{61}$ Puceianti, Nuovo Cimento (6), 4, p. 322, I912.

${ }^{52}$ Keene, Proc. Roy. Soc., 88 A, p. 40, 1913; London Electrician, 70, p. 54r, 1912.

${ }^{63}$ Shakespear, Proc. Roy. Soc. London, 86 A, p. I80, InI2.

${ }^{64}$ Todd, Proc. Rny. Soc., 83 A, p. 19, 190\%.

${ }^{65}$ Westphal, Verh. d. Deutsch. Phys. Gesell., 14, p. $9^{87}$, 1912.

${ }^{66}$ Westphal, Verh. d. Deutsch. Phys. Gesell., 15, p. 897, 1913.

${ }^{67}$ L.ewis and Adams, Phys. Rev. (2), 3, p. 92, I914.

${ }^{68}$ Millikan, Phys. Rev., 7, p. 379, xو16.

${ }^{69}$ Paschen, Sitzber, Akad. Wiss., Berlin, 21, pp. 403 and 959, 1899.

${ }^{70}$ Pasehen, Ann. der Phys. (4), 4, p. 277, 1901.

${ }^{71}$ Lummer and Pringsheim, Verh. Phys. Gesell., 1, p. 23, 1899.

${ }^{72}$ I,ummer and Jahnke, Ann. der Phys. (4), 3, p. $3^{8} 3$, I900.

${ }^{73}$ Lummer and Pringsheim, Verh. Phys. Gesell., 1, p. $215,1899$.

${ }^{74}$ Holborn and Valentiner, Ann. der Phys. (4), 22, p. I, Igo6.

${ }^{75}$ Valentiner, Ann. der Phys. (4), 29, p. 489, I912.

${ }^{76}$ Coblentz, B. S. Bul., 13, p. 459, 1916.

77 Rubens and Kurlbaam, Ann. der Phys. (4), 4, p. 649, I901.

${ }^{78}$ Nernst and Wulf, Verh. Phys. Gesell., 21, p. 294, 1919.

$7^{\circ}$ Warburg, Hupka, and Müller, Zs. Inștrk., 32, p. 134, 1912.

${ }^{80}$ Dellinger, B. S. Bul., 13, p. 535, 1916.

${ }^{81}$ Roeser, B. S. Bul., 14, p. 237 , 1917 (least square caleulation of $C$ ).

s2 Lummer and Pringsheim, Verh. Phys. Ges., 2, p. 163, Igoo.

${ }^{83}$ I,ummer and Pringsheim, Ann. der Phys. (4), 3, p. I59, I900.

${ }^{84}$ Holborn and Day, Ann. der Phys. (3), 68, p. 8ז7, IS99; Ann. der Phys. (4), 2, p. 505,1900 .

${ }_{85}$ Hoffınann and Meissner, Zs. für Instrk., 33, p. 157, I913.

${ }^{86}$ Warburg and Leithauser, Sitzber., 44, p. 225, 1910.

${ }^{87}$ Warburg and I,eithauser, Zs. für Instrk., 30, p. I18, I9Io.

${ }^{88}$ Warburg and Leithauser, Zs. für Instrk., 31, p. 124, I9I1.

${ }^{89}$ Warburg, Hupka, and Müller, Zs. für Instrk., 32, p. I34, I912.

${ }^{90}$ Warburg, Leithauser, Hupka, and Müller, Sitzer Akad. Wiss. Berlin, 1, p. 35, 1913 .

${ }_{91}$ Warburg, Leithanser, Hupka, and Müller, Ann. der Phys. (4), 40, p. 60g, 1913.

92 Warburg, Hupka, and Müller, Zs. Instrk., 34, p. II 5, I9I4.

${ }_{93}$ Warburg and Müller, Zs. Instrk., 35, p. 98, 101 5 .

${ }^{91}$ Warburg and Müller, Ann. der Phys. (4), 48, p. 410, I9r 5 .

${ }_{95}^{5}$ Warburg, Verh. Phys. Ges., 18, p. I; January, rgi6.

${ }^{96}$ Hoffmann and Meissner, Ann. der Phys. (4), 60, p. 201 , 1919.

${ }^{97}$ Holst and Oosterhuis, Proc. K. Akad., Amsterdain, 19, $\mu .549$, 1917.

${ }^{98}$ Hyde and Forsythe, Phys. Rev., 15, p. 540, 1920.

${ }^{99}$ Carvallo, Compt. Rend., 126, p. 728, 1898.

${ }^{100}$ Pasehen, Ann. der Phys. (4), 26, p. I20, 1908.

101 Paschen, Aun. der Phys. (4), 4, p. 299, I001, Fl. II.

102 Blake and Durane, Phys. Rev. (2), 10, p. 624, 1917.

${ }^{103}$ Hennig, Verh. Dentsch. Phys. Gesell., 20, p. 8I, 1918.

${ }^{104}$ Birge, Phys. Rev. (2), 14, p. 361, I9I9.

${ }^{105}$ Coblentz, B. S. Bul., 15, p. 617 , 1920.

${ }^{106}$ Gerlach, Zs. für Physik, 2, p. 76, I920.

${ }^{107}$ Coblentz, Phys. Rev. (2), 14, p. I74, 1919.

${ }^{208}$ Foote, B. S. Bul., 14, p. 605, 1918.

WASHINGTON, August 22, 1920. 